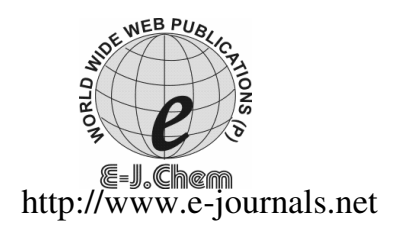

ISSN: 0973-4945; CODEN ECJHAO

E-Journal of Chemistry 2012, 9(1), 345-353

\title{
Removal of Lead from Synthetic Solutions by Protonated Teleosts Biomass
}

\author{
MUHAMMAD AQEEL ASHRAF ${ }^{{ }^{*}}$, MOHD. JAMIL MAAH $^{\S}$ and ISMAIL YUSOFF \\ ${ }^{\S}$ Department of Chemistry, \\ University of Malaya, Kuala Lumpur-50603, Malaysia \\ Department of Geology, \\ University of Malaya, Kuala Lumpur-50603, Malaysia \\ chemaqeel@gmail.com
}

Received 29 April 2011; Accepted 14 July 2011

\begin{abstract}
Lead is considered as a general protoplasmic poison which is cumulative and slow acting. It is used in different industrial processes. Its contamination in water may cause serious environmental problems. So removal of lead from environment is very necessary. For its removal the most suitable and cheapest process is biosorption. It is a process of passive metal binding by biomass. The biosorbent used in this study is teleosts biomass (fish scales) collected from local market. The purpose of this study is to search the effect of acid treatment on biosorbent and to optimize conditions for the uptake capacity of biosorbent. The optimal conditions for the $\mathrm{Pb}^{2+}$ biosorption capacity of teleosts biomass (fish scales as waste of white meat) was investigated. For this purposes, the biomass was subjected to chemical treatments with mono, di and tri-protic acids such as hydrochloric acid, sulphuric acid and phosphoric acid. Among the treatment methods used, the highest $\mathrm{Pb}^{2+}$ uptake was obtained with hydrochloric acid treatment of biomass. The effect of $\mathrm{pH}$, biomass granular size, biomass concentration and initial $\mathrm{Pb}^{2+}$ ion concentration was studied. The highest $\mathrm{Pb}^{2+}$ removal (65.39\%) was obtained at $\mathrm{pH} 4.0$ for $50 \mathrm{mg} \mathrm{L}^{-1}$ initial lead ion concentration with biomass granular size 80 micron and concentration of $0.05 \mathrm{~g}$. The uptake was $75.70 \mathrm{mg} \mathrm{g}^{-1}$. The equilibrium data were analyzed using the Langmuir and Freundlich adsorption isotherm. The characteristic parameters for each isotherm were determined. Both the isotherms provided the best correlation for $\mathrm{Pb}^{2+}$ on to the biomass. These results showed that teleosts biomass (fish scales) is a potential biomass to remove $\mathrm{Pb}^{+2}$ ions from synthetic solutions so also with lead contaminated water. These values can be compared with those observed for other biosorbents and it is considerably higher than the value obtained with the majority of the biosorbent.
\end{abstract}

Keywords: Protonated, Teleosts, Biomass, Removal 


\section{Introduction}

Contamination of aquatic bodies by various pollutants (synthetic and organic) such as pesticides, poly-aromatic hydrocarbons, heavy metals, etc., have caused imbalance in the natural functioning of ecosystem. Among these, heavy metals cause severe damage to living systems at various levels. Heavy metals enter the water supply by industrial and consumer wastes or even from acid rain breaking down soil and rocks and releasing heavy metals into streams, lakes and ground water ${ }^{1}$. Among these heavy metals lead is particularly toxic element, which has conservative and cumulative characteristics ${ }^{2}$ and can severely affect brain, kidneys, reproductive systems, and cardiovascular system. Great exposures can cause impairments in intellectual functioning, kidney damage, infertility, miscarriage, and hypertension ${ }^{3}$.

Conventional methods for removing dissolves heavy metal ions from wastewater include chemical precipitation, chemical oxidation and reduction, ion exchange, filtration, electrochemical treatment and evaporative recovery. These techniques have significant disadvantages including incomplete metal removal, the need for expensive equipment and monitoring systems, high reagent or energy requirements or generation of toxic sludge or other waste products that require disposal ${ }^{4}$.

Biosorption is a process in which solids of natural origin are employed for binding of heavy metals ${ }^{5}$. The major advantages of biosorption over conventional treatment methods include: Low cost; High efficiency; minimization of chemical and or biological sludge; no additional nutrients requirement; regeneration of biosorbent and possibility of metal recovery. The biosorption process involves a solid phase (sorbent or biosorbent; biological material) and a liquid phase (solvent, normally water) containing dissolved species to be sorbed (sorbate, metal ions) due to higher affinity of biosorbent for the sorbate species, the later is attracted and bound there by different mechanisms ${ }^{6}$.

\section{Objectives and significance}

Metal affinity can be manipulated by pretreating the biomass with alkalies, acids, detergent and heat, which may increase the amount of metal sorbed. Thus, this investigation studies the use of a non-useful animal material as naturally occurring biosorbent for the removal of lead ion in the aqueous solution. The sorbent used in the present study is teleosts biomass gained from fresh water fish scales. The scales of fish have the bioaccumulation characteristic for metal (lead, copper, zinc and arsenic). The principal objective of present work is to report screening of efficient protonated biosorbent and to study the effect of different conditions that are biomass size, concentration, $\mathrm{pH}$ and time required for the establishment of equilibrium.

\section{Experimental}

The teleosts biomass used in this study was collected from local market. The biomass was washed with detergent and distilled water to remove any foreign dust particles. It was dried at $60^{\circ} \mathrm{C}$ in the electric oven and ground using grinder (Heptech). Soaking $25 \mathrm{~g}$ biomass in excess $0.1 \mathrm{M} \mathrm{HCl}, 0.1 \mathrm{M} \mathrm{H}_{2} \mathrm{SO}_{4}$ and $0.1 \mathrm{M} \mathrm{H}_{3} \mathrm{PO}_{4}$ in three conical flasks each, treated the ground biomass. The flasks were agitated for 20 hours in orbital shaker (PA250/25H) at 100 $\mathrm{rpm}$, followed by washing thoroughly with distilled water until a $\mathrm{pH}$ of 6.8-7.0 was attained and then dried and again ground to finely grinded powdered biomass. 


\section{Biosorption studies}

Biosorption experiments were carried out using $\mathrm{Pb}^{2+}$ containing solution added in the form of $\mathrm{Pb}\left(\mathrm{NO}_{3}\right)_{2}$ prepared in the distilled water. The inlet $\mathrm{Pb}^{2+}$ concentration was about $100 \mathrm{mg} \mathrm{L}^{-1}$. Adding $0.05 \mathrm{~g}$ of treated and untreated biomass carried out the first screening biosorption experiment in the orbital shaker at $100 \mathrm{rpm}$ for 20 . The effect of $\mathrm{pH}$ biomass granular size, initial concentration of $\mathrm{Pb}^{2+}$ ion and biomass concentration were determined for biosorbent prepared from $\mathrm{HCl}$ treated biomass with the highest metal uptake was obtained.

The effect of $\mathrm{pH}$ on biosorption was investigated in the $\mathrm{pH}$ range of 2.0-6.0. $\mathrm{pH}$ value higher than 6 and less than 2 could not be used due to rapid precipitation of $\mathrm{Pb}^{2+}$ ion. The $\mathrm{pH}$ values of $\mathrm{Pb}^{2+}$ solutions were adjusted to the desired value with either $0.1 \mathrm{M} \mathrm{HNO}_{3}$ or $0.1 \mathrm{M} \mathrm{NaOH}$ solution.

Analysis of $\mathrm{Pb}^{2+}$ ions

The concentration of unabsorbed $\mathrm{Pb}^{2+}$ ions in the biosorption medium was determined with Perkin Elmer atomic absorption spectrophotometer (AA300) fitted with hollow cathode lamp of lead at $283.3 \mathrm{~nm}$.

\section{Data analysis}

The percent removal of metal ion by teleosts biomass was calculated using the equation:

$$
\% R \frac{C_{i}-C_{f}}{C_{i}} \times 100
$$

Where $R$ is removal and $C i$ and $C_{f}$ are the initial and final metal ions concentration in the solution. The capacity of biosorbent for metal ions was determined at different concentrations in $\mathrm{mg} \mathrm{g}^{-1}$ was calculated from the following relationship:

$$
\text { Capacity }(\mathrm{mgg}-1)=\frac{\% \mathrm{R}}{100} \times \mathrm{Ci} \times \frac{\mathrm{V}}{\mathrm{m}}
$$

Where $\mathrm{V}$ is the volume of metal ion solution used and $\mathrm{m}$ is the amount of biomass used (g). The linearized Langmuir isotherm model below was used to describe the sorption of metal onto metal surface:

$$
1 / \mathrm{q}_{\mathrm{e}}=1 / \mathrm{q}_{\max }+1 /\left(\mathrm{b} \cdot \mathrm{q}_{\max } \cdot \mathrm{C}_{\mathrm{e}}\right)
$$

\section{Results and Discussion}

\section{Screening studies}

Uptake capacity and percent removal of lead by the biosorbent treated with different acids were screened separately. Results in Figure 1 depict that $\mathrm{HCl}$ treated biosorbent showed maximum uptake capacity ( $\mathrm{q}$ value in $\mathrm{mg} \mathrm{g}^{-1}$ ) and \% removal of $\mathrm{Pb}^{2+}$. This is attributed to the binding of $\mathrm{H}^{+}$ions to the biomass after acid treatment may be responsible for the reduction in adsorption of heavy metal. The polymeric structure of biomass surface exhibits negative charge due to ionization of organic and inorganic groups ${ }^{7}$.

$\mathrm{HCl}$ being a mono-protic acid cannot change much the electro-negativity of biomass so $\mathrm{HCl}$ treated biomass showed maximum uptake capacity and \%age removal for $\mathrm{Pb}^{2+}$ as compared to other biosorbents that were treated with di-protic and tri-protic acids i.e. $\mathrm{H}_{2} \mathrm{SO}_{4}, \mathrm{H}_{3} \mathrm{PO}_{4}$. This was also according to results of Cabuk et al., ${ }^{8}$. An increase in biosorption of lead ions as a result of acid treatment could be due to more exposure of active metal binding sites ${ }^{9}$. 


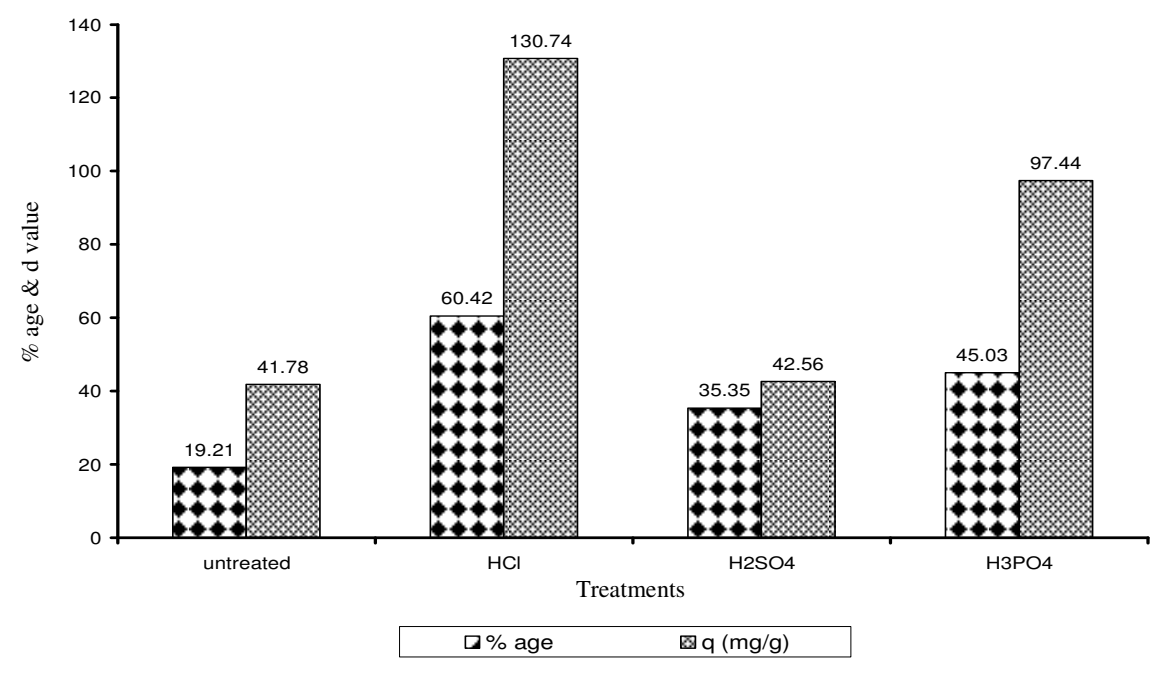

Figure 1. Screening studies of Lead removal by protonated teleosts biomass

\section{Effect of $p H$}

Biosorption of lead depends upon $\mathrm{pH}$ shown in Figure 2 that $\mathrm{pH}$ of the medium affects the solubility of metal ions and also the functional groups of the biosorbent. Thus maximum sorption of lead for $\mathrm{HCl}$ treated biosorbent increased with the increase of $\mathrm{pH}$ from 2 and the lead sorption reached maximum at $\mathrm{pH}$ 4. This agreed with the previous results for Ecklonia radiata (brown marine algae) as a biosorbent ${ }^{10}$. As shown in Figure 2 that uptake capacity for $\mathrm{HCl}$ treated biosorbent was $111.6 \mathrm{mg} \mathrm{g}^{-1}$, for $\mathrm{H}_{2} \mathrm{SO}_{4}$ treated was $57.82 \mathrm{mg} \mathrm{g}^{-1}$ and for $\mathrm{H}_{3} \mathrm{PO}_{4}$ was $79.54 \mathrm{mg} \mathrm{g}^{-1}$. At $\mathrm{pH} 2$ and $\mathrm{pH} 6$ lead solution precipitated making true sorption studies impossible so these experiments did not take the consideration. At low pH lead removal was inhibited possibly as a result of competition between $\mathrm{H}^{+}$and lead ions on the sorption sites with an apparent preponderance of $\mathrm{H}^{+}$, which restrict the approach of metal cations as in consequence of the repulsive force. As the $\mathrm{pH}$ increased to four the ligands i.e. carboxylate groups in collagen would be exposed increasing the negative charge density on the biomass surface, increasing the attraction of metallic ions with positive charge and allowing the biosorption on the surface of the biosorbent. Rising of $\mathrm{pH}$ above four the $\mathrm{Pb}^{+2}$ ions started precipitated to $\mathrm{Pb}(\mathrm{OH})_{2}$ due to increasing concentration of $\mathrm{OH}^{-1}$ in solution.

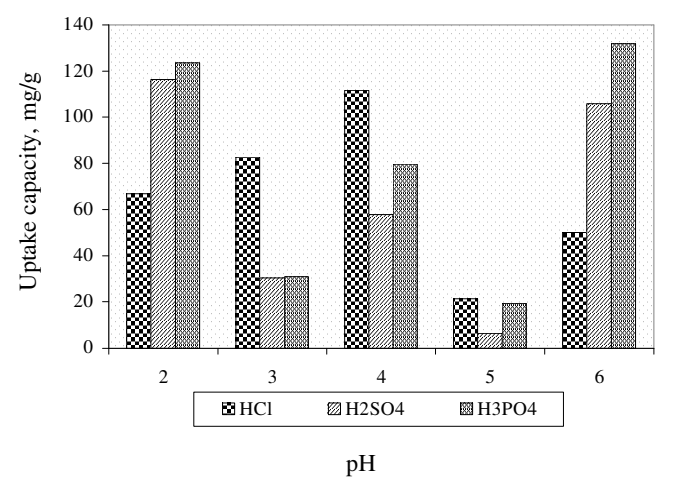

Figure 2. Screening studies of Lead removal at different $\mathrm{pH}$ by protonated teleosts biomass 


\section{Effect of biosorbent granular size}

The experiment conducted in order to see the effect of biosorbent granular size showed that larger the granular size, smaller is the sorption and smaller the granular size greater is the sorption ${ }^{11}$. This is shown in figure 3 that the \%age removal for 63,80 and 150 micron sizes was $56.24,59.17$ and 45.05 respectively. In the similar way biosorbent with 80 micron size had highest uptake capacity i.e. $157.40 \mathrm{mg} \mathrm{g}^{-1}$, these results agree with the previous results on biosorption of zinc by Rhizopus arrhizus ${ }^{12}$.

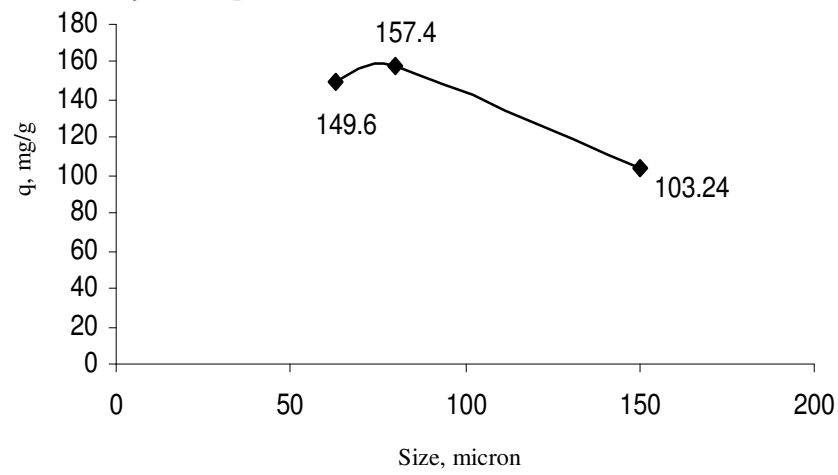

Figure 3. Effect of biosorbent size on uptake capacity

\section{Effect of solution concentration}

Previous results on biosorption of metal shows that more metal uptake capacity occurred by increasing the metal ion concentration. It is clear from results as shown in Figure 4 that for $30.95,63.9,113,245,421.6,634.6$ and $847.8 \mathrm{mg} \mathrm{L}^{-1}$ initial concentration of solution, the uptake capacity is $38.86,91.3,101.22,302.08,311.2,588.2$ and $415.6 \mathrm{~L}^{-1}$ respectively after $24 \mathrm{~h}$ at $\mathrm{pH} 4$, granular size 150 micron. This size was selected because of insufficient quantity availed during sieving. These results are in agreement with the results obtained by different researchers ${ }^{13-15}$. The sorption characteristics indicated that surface saturation was dependent on initial metal ion concentration. At low concentration, adsorption sites took up the available metal more quickly. However, at higher concentration metals need to diffuse to the biomass surface by intra-particle diffusion and greatly hydrolyzed ions will diffuse at a slower rate.

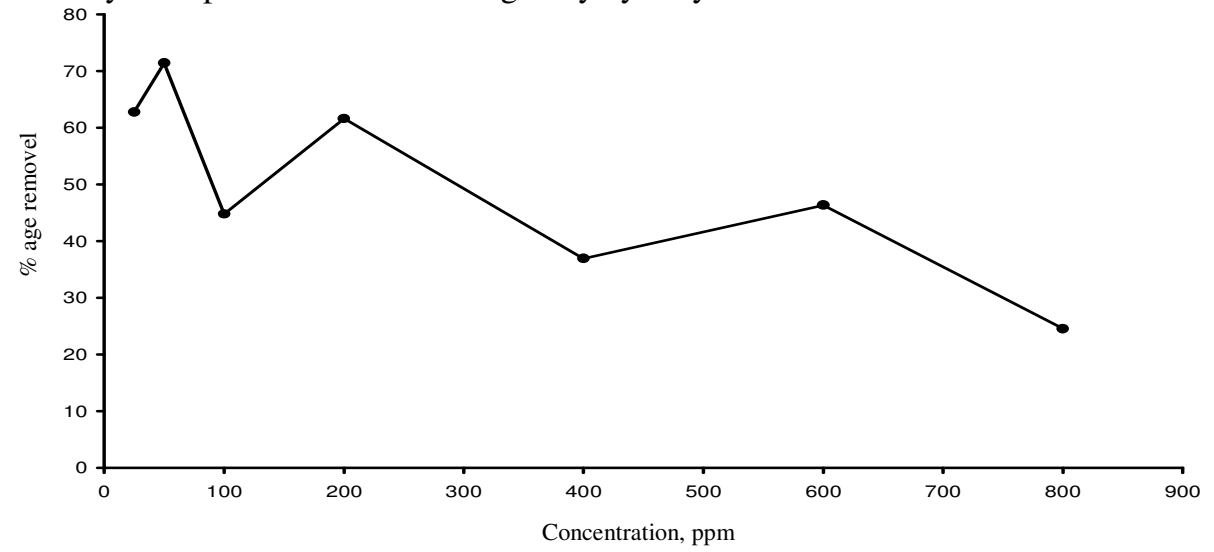

Figure 4. Studies for effect of initial metal concentration on lead removal using protonated teleosts biomass 


\section{Effect of biosorbent amount on lead removal}

Figure 5 showed that increase of biomass concentration increased the uptake capacity. This was maximum for $0.05 \mathrm{~g}$ of biomass concentration. For lower values of biomass concentration there is an increase in the specific uptake ${ }^{16-17}$. According to Gadd ${ }^{17}$ increasing the biomass concentration leads to interference between binding sites. Uptake capacity of $80 \mu$ biosorbent granular size and at $\mathrm{pH} 4$ for $0.01,0.02,0.05,0.1$ and $0.15 \mathrm{~g}$ of biosorbent amount was $213.95,170.33,75.70,33.59$ and $20.76 \mathrm{mg} \mathrm{g}^{-1}$ that was maximum for $0.05 \mathrm{~g}$ biosorbent concentration. Fourest and Roux attributed the responsibility of specific uptake decrease to metal concentration shortage in solution ${ }^{16}$.

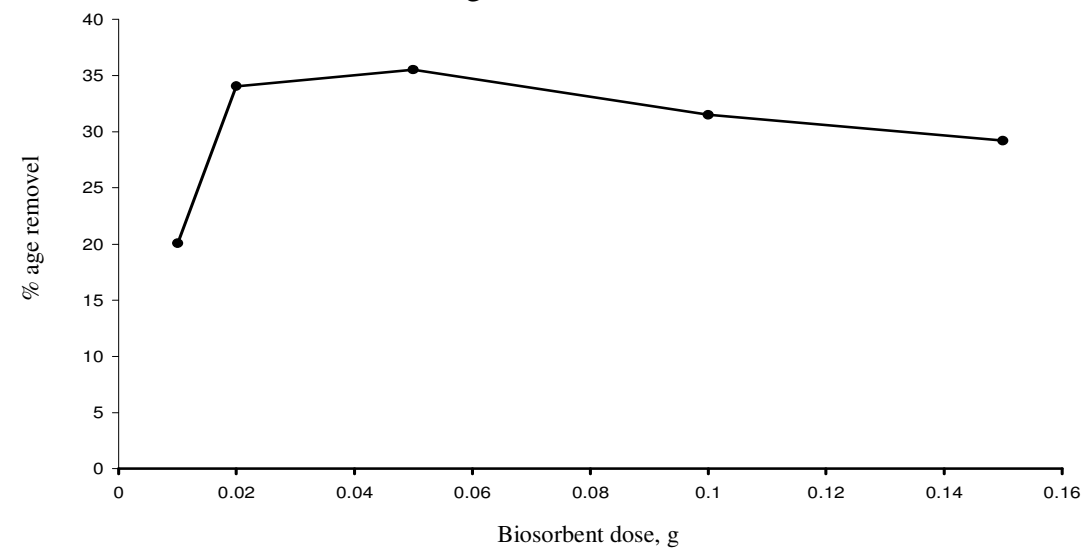

Figure 5. Studies for effect of biosorbent dose on lead removal using protonated teleosts biomass

\section{Effect of time interval on biosorption}

The dependence of lead biosorption on time is shown in Figure 6. Generally it is reported that uptake of metal ions can be divided in two stages; rapid and slow stage. In rapid stage the metal ions are absorbed on to the surface of biosorbent. In the slow stage, the metal ions transport across the cell membrane ${ }^{18}$.

The results declared that rapid stage sorption took place within the first fifteen minutes of contact time with uptake capacity of $49.20 \mathrm{mg} \mathrm{g}^{-1}$ and slow stage sorption for the next 105 minutes. More than $50 \%$ metal ions were removed during the rapid sorption stage. The Figure 6 shows the equilibrium attained and no desorption took place up to the end of contact time of 480 minutes.

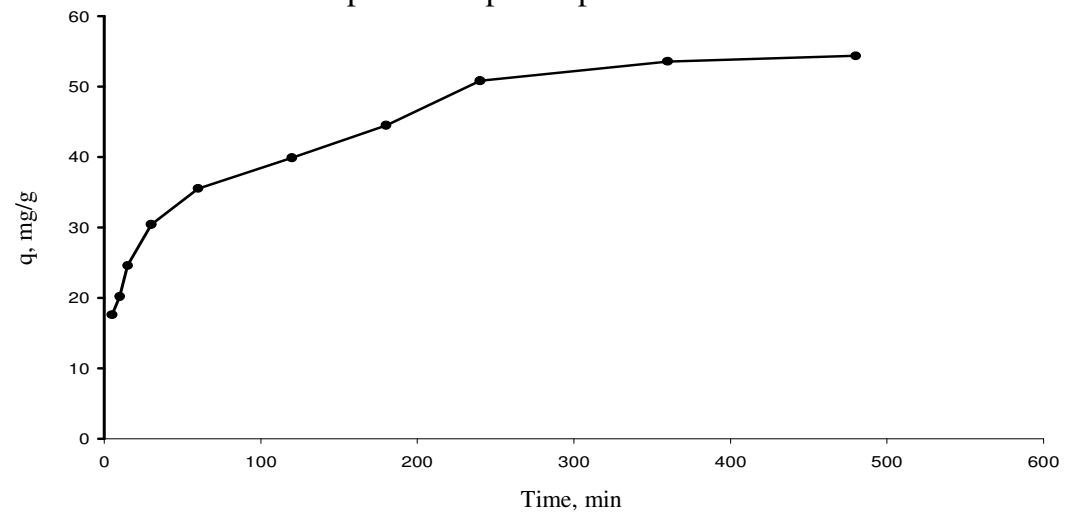

Figure 6. Effect of time interval on biosorption 


\section{Equilibrium Modeling}

The equilibrium of the biosorption process is often described by fitting the experimental points with two models usually used for the representation of isotherm adsorption equilibrium.

The Langmuir model makes assumptions such as monolayer adsorption and constant adsorption energy while the Freundlich model deals with heterogeneous adsorption ${ }^{19-20}$. The biomass exhibited Langmuir and Freundlich adsorption isotherm, which is the characteristics of the biomass substrate containing both micropores and mesopores ${ }^{21-22}$. In general the data indicated that the sorption capacity of biomass increased with the increase in the initial concentration of metal ions. This sorption characteristic indicates that surface saturation was dependent on the initial metal ion concentration. At low concentration adsorption site took the metal ion more quickly. However at high concentration metal needed to diffuse the biomass surface by intraparticle diffusion and greatly hydrolyzed ions were diffused at slow rate. If the metal ions are taken up independently on a single type of binding site in such a way that the uptake of the first metal ion does not affect the sorption of the next ion, then the sorption process would follow the Langmuir adsorption isotherm ${ }^{23}$ which is linearized to the form

$$
1 / \mathrm{qe}=1 / \mathrm{q}_{\max }+1 /\left(\mathrm{bq}_{\max } \cdot \mathrm{Ce}\right)
$$

Where, $\mathrm{q}_{\max }$ and $\mathrm{b}$ are the Langmuir constants. Figure 7 shows the data linearized to Langmuir equation. The plot of $1 / \mathrm{C}_{\mathrm{e}} v s .1 / \mathrm{q}_{\mathrm{e}}$ gave the linear isotherm parameters of $\mathrm{q}_{\max }$ and b. The value of coefficient of determination $\mathrm{R}^{2}$ suggests that the Langmuir isotherm provides the model of monolayer sorption system ${ }^{24-25}$.

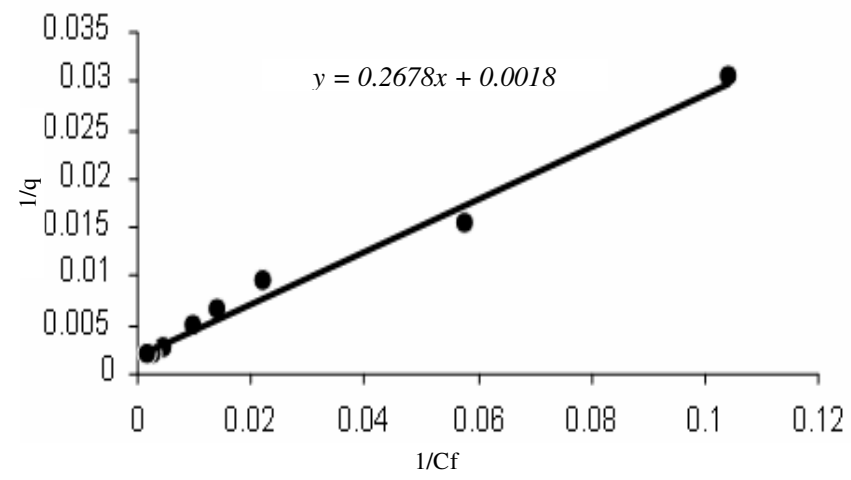

Figure 7. Langmuir Isotherm plot for biosorption of lead

The Freundlich equation is another model shown in Figure 8 has been commonly used to describe adsorption isotherm. Its linearized form is represented by the equation

$$
\log \mathrm{q}_{\mathrm{e}}=\log \mathrm{K}+1 / \mathrm{n} \log \mathrm{C}_{\mathrm{e}}
$$

Where $\mathrm{q}$ is the amount adsorbed per unit mass of adsorbent and $\mathrm{Ce}$ is equilibrium concentration. The plot of $\log \mathrm{q}_{\mathrm{e}} v s . \log \mathrm{C}_{\mathrm{e}}$ is linear and constants $\mathrm{K}$ and $\mathrm{n}$ can be evaluated from slopes and intercepts ${ }^{26-27}$.

It was found that the adsorption equilibrium data were better fitted by the Langmuir isotherm, although it can also be modeled by the Freundlich isotherm, in the concentration range studied. 


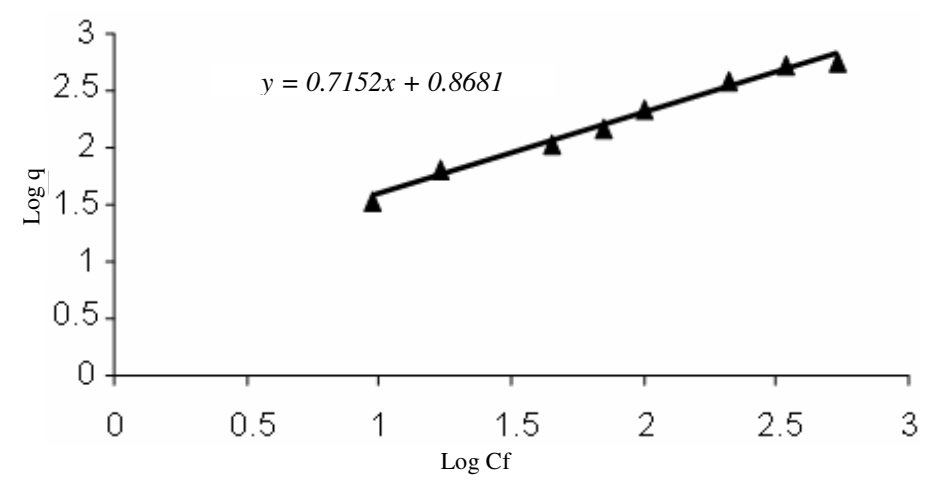

Figure 8. Freundlich Isotherm plot for biosorption of lead

\section{Conclusion}

The results showed that teleosts biomass (fish scales) is a potential biomass to remove $\mathrm{Pb}^{+2}$ ions from synthetic solutions so also with lead contaminated water. These values can be compared with those observed for other biosorbents and it is considerably higher than the value obtained with the majority of the biosorbent.

\section{Acknowledgement}

The work reported in this paper is a basic research work carried out at Analytical Laboratory, Department of Chemistry and at Department of Geology, University of Malaya. Gratitude to Ministry of Higher Education, Malaysia for providing scholarship to Ashraf, M.A. and University of Malaya for funding the project (PS355/2009C).

\section{References}

1. Kar R N, Sahoo B N and Sukla L B, Poll Res., 1992, 11, 1.

2. Ho Y S, John Vase D A and Forster CF, Environ Technol., 1996, 17, 71.

3. Silbergd E K, Int J Occup Environ Health, 1995, 1, 338.

4. Aksu Z, Egretli G and Kutsal T, J Environ Sci Health A, 1999, 34, 295.

5. Cossish E S, Tavares C R G and Ravagnani T M K, Process Biotechnol., 2002, 5, 71.

6. Kratochvil D and Velosky B , Water Res., 1998, 32, 2760.

7. Hughes M N and Poole R K, Chapman and Hall, London, New York, 1989, 10.

8. Cabuk M, Alcicek A, Bozkurt M and Imre N, II. National Animal Nutrition Congr., Konya, Turkey, 2003, 184.

9. Huang C and Huang C P, Water Res., 1996, 30, 1985.

10. Matheickal, Jose $\mathrm{T}$ and Qiming Ye, Presented at School of Environmental Engineering, 1996.

11. Cribasi I H and Yetis U, Water SA, 2001, 27, 15.

12. Zhou J L, Appl Microbiol Biotechnol.,1999, 51, 686.

13. Kapoor A and Viraraghvan T, Bioresour. Technol., 1998, 63, 109.

14. Khalid N S, Ahmad Kiani S N and Ahmad J, Sep Sc Technol., 1998, 33, 2349.

15. Hui Niu, Xue, Shu and Jian Huawang, Biotechnol Bioengg., 1998, 42, 110.

16. Fourest E and Roux C J, App Microbiol Biotechnol., 1992, 37, 399.

17. Gadd G M, Experentia, 1990, 46, 834-840,

18. Dara S S, Baneji prentice Hall of India (Pvt.) New Delhi, 1998, 64. 
19. Kumar U and Karkani M B, Agrobios (India), Jodhpur, 2001, 5.

20. Passwater R A and Cranton E M, New Canaan, CT: Keasts, 1983.

21. Galun M, Keller P, Malki D and Seigel B Z, Science, 1983, 219, 285.

22. Ward N I, Heavy metals in the Environment, CEP Consultants, Edinburgh, 1996, 227.

23. Tiwari V, Ghoparde B and Vankar P S, Colourage. 2000, 47, 18.

24. Zhan X M and Zhao X, Water Res., 2003, 37, 3905.

25. Chong K H and Volesky B, Biotechnol Bioeng., 1995, 47, 1.

26. Miyazaki A and Makano Y, J Environ Sci., 2003, 15, 102.

27. Farajzadeh M A and Vardast M R, J Chinese Chem Soc., 2003, 50, 245. 


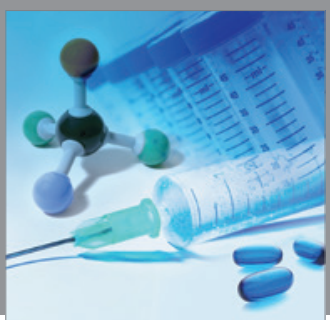

International Journal of

Medicinal Chemistry

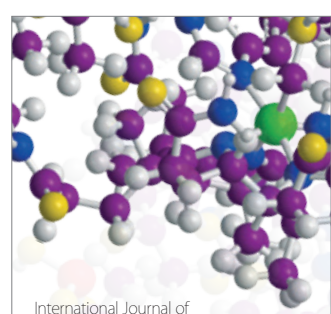

Carbohydrate Chemistry

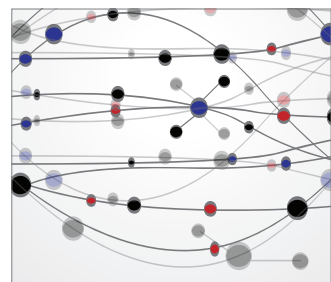

The Scientific World Journal
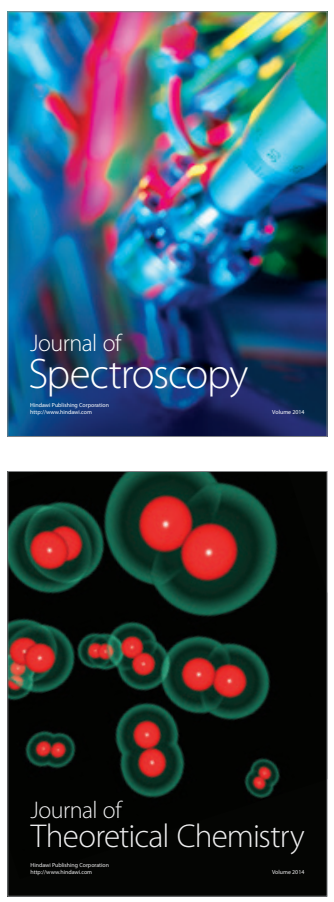
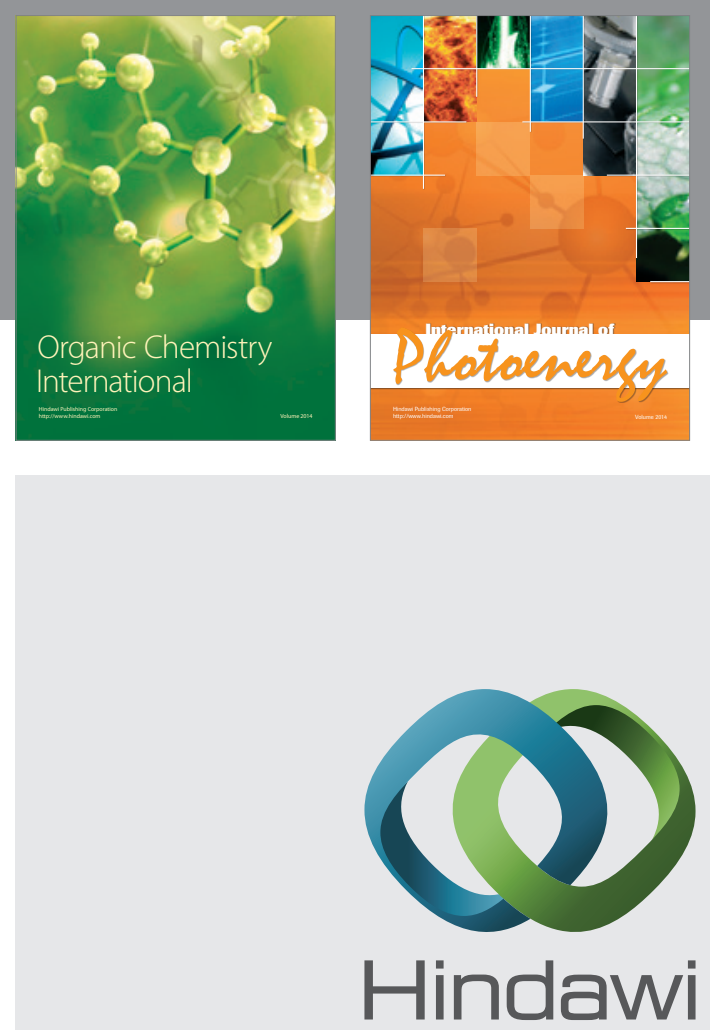

Submit your manuscripts at

http://www.hindawi.com
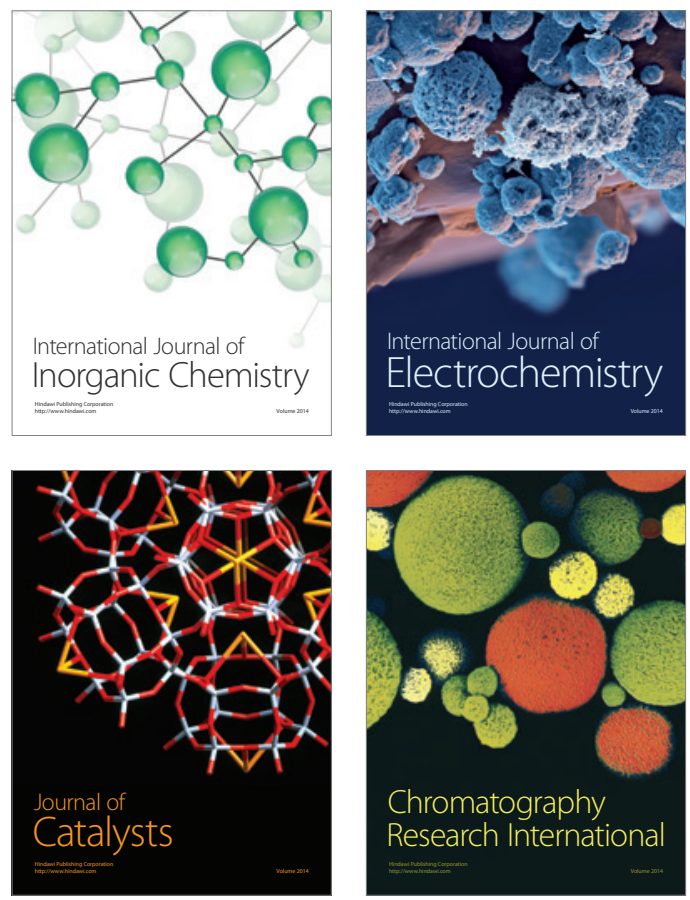
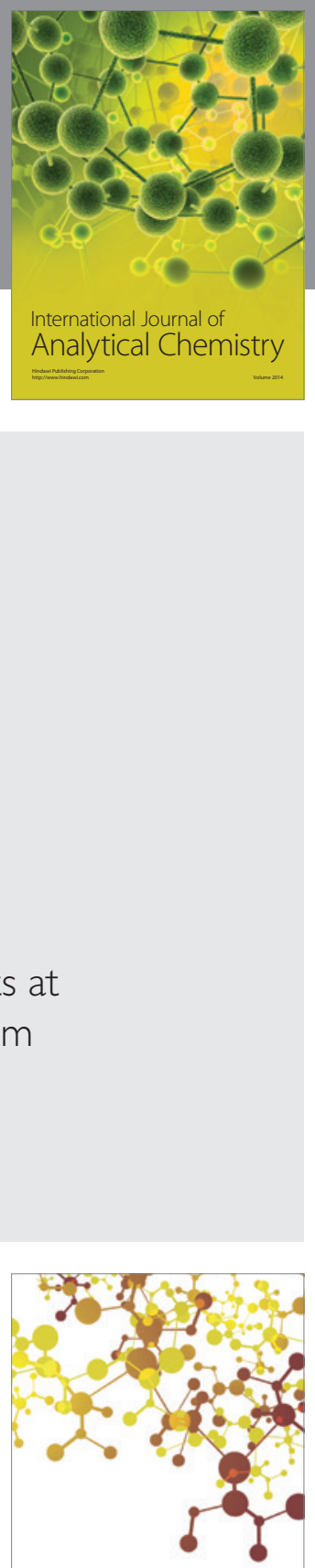

Journal of

Applied Chemistry
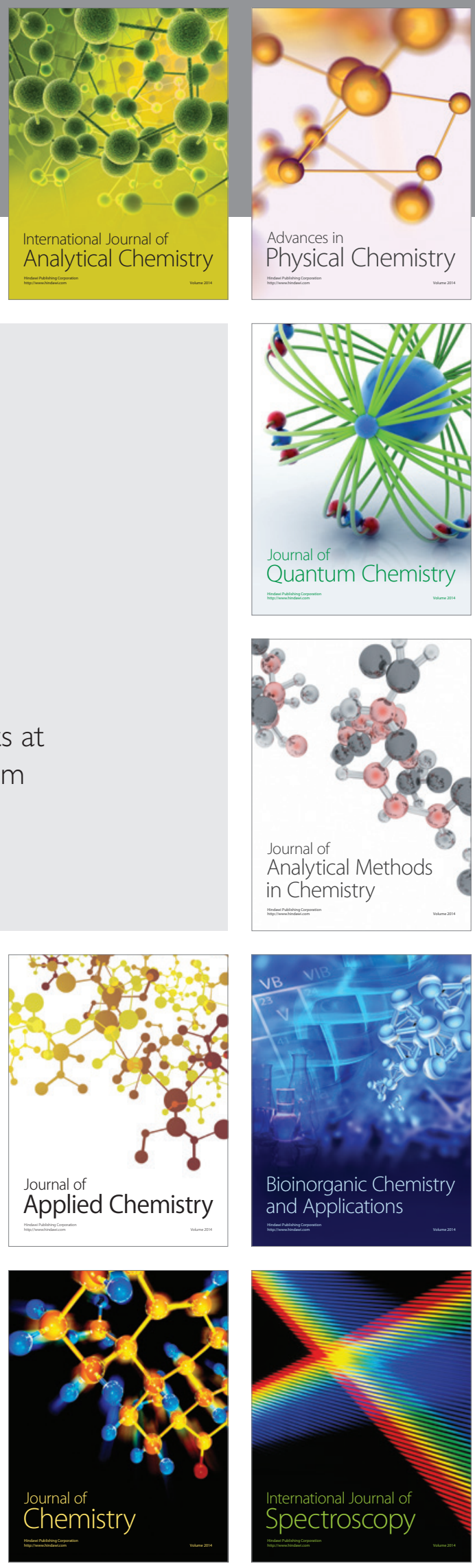